\title{
Tackling mantle cell lymphoma (MCL): Potential benefit of allogeneic stem cell transplantation
}

This article was published in the following Dove Press journal:

Stem Cells and Cloning:Advances and Applications

3 July 2010

Number of times this article has been viewed

\author{
Satish Shanbhag ${ }^{1,2}$ \\ Mitchell R Smith' \\ Robert VB Emmons ${ }^{2}$ \\ 'Department of Medical Oncology, \\ Fox Chase Cancer Center, ${ }^{2}$ Division \\ of Bone Marrow Transplantation, \\ Temple University, Philadelphia, \\ PA, USA
}

\begin{abstract}
Mantle cell lymphoma (MCL) is a type of non-Hodgkins lymphoma (NHL) associated with poor progression-free and overall survival. There is a high relapse rate with conventional cytotoxic chemotherapy. Intensive combination chemotherapy including rituximab, dose intense CHOP- (cyclophosphamide-doxorubicin-vincristine-prednisone) like regimens, high dose cytarabine, and/or consolidation with autologous stem cell transplant (autoSCT) have shown promise in significantly prolonging remissions. Data from phase II studies show that even in patients with chemotherapy refractory MCL, allogeneic stem cell transplant (alloSCT) can lead to long term disease control. Most patients with MCL are not candidates for myeloablative alloSCT due to their age, comorbidities, and performance status. The advent of less toxic reduced intensity conditioning (RIC) regimens, which rely more on the graft-versus-lymphoma (GVL) effect, have expanded the population of patients who would be eligible for alloSCT. RIC regimens alter the balance of toxicity and efficacy favoring its use. Treatment decisions are complicated by introduction of novel agents which are attractive options for older, frail patients. Further studies are needed to determine the role and timing of alloSCT in MCL. Currently, for selected fit patients with chemotherapy resistant MCL or those who progress after autoSCT, alloSCT may provide long term survival.
\end{abstract}

Keywords: mantle cell lymphoma, allogeneic SCT, nonmyeloablative, GVL

Mantle cell lymphoma (MCL) is a unique subtype of mature B-cell non-Hodgkin's lymphomas (NHL) with a high response rate but an equally high relapse rate and relatively poor median survival. MCL can exhibit a spectrum of clinical courses. At one end of the spectrum is a chronic lymphocytic leukemia (CLL) like disease with a true chronic course where observation alone is warranted. ${ }^{1}$ At the other end is an aggressive disease that displays rapid growth, relative chemoresistance, and early relapse. Generally, when treatment is necessary MCL usually exhibits shorter progression-free intervals compared to other indolent NHL. The wide variability in clinical behavior has increased treatment and prognostic uncertainty. This variability is reflected in its inclusion as an aggressive lymphoma in the Revised European-American Lymphoma (REAL) classification, ${ }^{2}$ yet it remains included with indolent lymphomas in many current European and some US studies.

MCL has recently emerged as a separate clinicopathologic entity critically dependent on the dysregulation of cyclin $\mathrm{D}$. The cytogenetic translocation $t(11 ; 14)$ (q13;q32) between the cyclin D1 (BCL-1 locus) and the immunoglobulin heavy chain (IgH) locus, which results in cyclin D1 dysregulation, is found in the majority of MCL cases. In the few cyclin D1 negative MCL, cyclin D2, D3, or both are overexpressed. 
MCL shares the $\mathrm{CD}^{+} \mathrm{B}$-cell immunophenotype of CLL, but is differentiated from CLL by having bright CD20 with high levels of surface immunoglobulin and lack of CD23 expression. Morphologically, the appearance of MCL can vary from a small mature lymphocyte to a more blastoid larger cell that mirrors its protean behavior.

\section{Mantle cell biology and behavior}

Attempts have been made to subclassify MCL based on its histopathology, ie, classic, small cell, pleomorphic, and blastoid variants. ${ }^{3}$ Patients with the blastoid variant often have the worst outcomes and those with the small cell type of MCL seem to do the best, but this has not yet defined a treatment algorithm to address each subtype separately. Rosenwald et al used gene expression profiling by microarray to predict survival of patients with MCL. While no specific gene correlated with survival, expression of a panel of proliferation signature genes allowed separation into four quartiles of patients in which the first and fourth quartiles differed by more than 5 years in median survival. ${ }^{4}$ Reports of other gene panels to predict MCL outcome are intriguing and require validation in other patient populations. ${ }^{5}$

Proliferation assessed by Ki67 staining remains an effective, readily available prognostic indicator. More precise quantification may make it even more useful. ${ }^{6}$ A Cancer and Leukemia Group B (CALGB) phase II trial showed that $>35 \% \mathrm{Ki}-67$ expression was associated with a shorter progression-free survival (PFS) and event-free survival (EFS) and PIM1 (a cell cycle-related gene) expression was associated with a shorter PFS. ${ }^{7}$ The German Low Grade Lymphoma study group (GLSG) developed the mantle cell lymphoma international prognostic index (MIPI) based on five prognostic factors: age, performance status, lactate dehydrogenase (LDH), leukocyte count, and $\mathrm{Ki} 67$ immunostaining index ${ }^{8}$ to classify MCL patients into three groups based on their overall survival (OS): low risk (median OS not reached), intermediate risk (51 months), and high risk groups (29 months). ${ }^{9}$ MIPI has, however, been variably predictive when applied to other intensively treated subsets of patients..$^{10,11}$

\section{Current standard therapy}

Analysis of outcomes data in MCL from trials conducted between 1975 to 1986 by the Kiel Lymphoma Study Group compared to trials conducted by the GLSG from 1996 to 2004 revealed an increase in median overall survival from 2.7 years to 4.8 years. Some of this improvement may be due to earlier and more specific diagnosis and better supportive care, but may also represent the improvements in MCL therapy with dose intense regimens and new therapeutic agents. ${ }^{12}$
The development of more intensive induction regimens, such as rituximab (a chimeric monoclonal anti-CD20 antibody) plus hyperfractionated cyclophosphamide and vincristine-doxorubicin-dexamethasone (R-HyperCVAD) with alternating dose intense chemotherapy combinations using high dose cytarabine, increased the reported percentage of complete responses (CR) and median PFS. ${ }^{13}$ Patient selection, however, may be an issue as two cooperative groups have been unable to effectively treat large numbers of patients with this regimen and there are no randomized data proving superior overall survival benefit compared to conventional anthracycline based chemotherapy (R-CHOP). Questions of improved long-term survival from dose intensification and addition of other cytotoxic agents remain unanswered, although recent evidence suggests there may be a subset of patients who gain a good long-term outlook with chemotherapy alone. ${ }^{13}$

The addition of rituximab has improved overall and complete response rates, ${ }^{14,15}$ but not necessarily overall survival. Relatively small numbers of patients in recent trials may have limited statistical power to detect a difference, although in a relatively large MCL trial (122 patients) conducted by the GLSG, Lenz et al were unable to show a significant improvement in PFS from addition of rituximab to CHOP despite increased CR and overall response rates. ${ }^{15} \mathrm{~A}$ Cochrane metaanalysis in 2007 led to researchers concluded that adding rituximab did improve OS, although there were only three trials included and these were heterogenous. ${ }^{16,17}$ Currently, the addition of rituximab has become a standard in the management of MCL first line in the United States (Table 1).

Table I First-line MCL regimens

\begin{tabular}{lcccll}
\hline Regimen & Year & n & RR\% & CR\% & $\begin{array}{l}\text { PFS/TTF } \\
\text { months }\end{array}$ \\
\hline COP versus CHOP'8 & 1989 & 37 & 84 & 41 & 7 \\
& & 26 & 89 & 58 & 10 \\
CHOP versus & 2005 & 122 & 75 & 7 & 14 \\
R-CHOP'5 & & & 94 & 34 & 21 \\
MCP versus CHOP'9 & 2006 & 86 & 73 & 20 & 15 \\
& & & 87 & 15 & 21 \\
R-CHOPI4 & 2002 & 40 & 96 & 48 & 16.6 \\
R-HyperCVAD-R-M/A & 2005 & 97 & 97 & 87 & 36 months \\
R-CHOP $\rightarrow$ RIT & & & & & FFS 73\% \\
\hline
\end{tabular}

Abbreviations: COP, cyclophosphamide-vincristine-prednisone; $\mathrm{CHOP}$, cyclophosphamide-doxorubicin-vincristine-prednisone; MCP, mitoxantrone-chlorambucilprednisone; $R R$, response rate; $C R$, complete response; PFS, progression-free survival; TTF, time to treatment failure; FFS, failure-free survival; HyperCVAD, hyperfractionated cyclophosphamide-vincristine-doxorubicin-dexamethasone; M/A, methotrexate/ cytarabine; R, rituximab; R-CHOP, rituximab-cyclophosphamide-doxorubicinvincristine-prednisone; RIT, radio immunotherapy; MCL, mantle cell lymphoma. 


\section{High-dose therapy with autologous stem-cell support}

A natural extension of the dose intensification approach is the use of high-dose therapy requiring stem cell support. This has now been studied in multiple trials, which have predominantly been single arm Phase II trials evaluating response rates (Table 2). The European MCL network's randomized trial comparing consolidation with myeloablative radiochemotherapy followed by autologous stem cell support (ASCT) to interferon- $\alpha$ maintenance in first remission showed a median PFS benefit ( 39 mos versus 17 mos, $P=0.01$ ) with ASCT. ${ }^{21}$ The absence of minimal residual disease (MRD) after ASCT, assayed by quantitative real-time PCR of clonal IgH gene rearrangements, strongly predicted for longer failure free interval. ${ }^{22}$ Autotransplant in CR1 (complete response after first-line therapy) following R-CHOP or similar regimens is currently adopted as one standard approach in patients fit to undergo high dose therapy.

In a large retrospective study of the Autologous Blood and Marrow Transplant Registry (ABMTR) and European Blood and Bone Marrow Transplant (EBMT) registry, transplanted patients had a median survival of 59 months, which is longer than historical (1990s) series of patients treated conventionally with a median survival of 36 months. ${ }^{23}$ Patients who received autotransplant in CR1 clearly did better than partial responders in the study. The addition of radioimmunotherapy holds promise in overcoming this difference by improving the degree of response prior to
autoSCT. ${ }^{24}$ Biologic markers are clearly needed to help stratify patients among treatment options and especially transplant options.

\section{Allogeneic transplant in indolent non-Hodgkin's lymphomas}

Indolent lymphomas are currently considered incurable by cytotoxic chemotherapy alone even at high doses. In selected patients allogeneic transplant may offer the potential for longer remission and potentially cure. The significant toxicity, both high early mortality rate and graft-versus-host disease (GVHD), with myeloablative regimens and allogeneic stem cell transplant (alloSCT) has limited the use of this modality. The development of less toxic (nonmyeloablative or reduced intensity conditioning, RIC) regimens and improved supportive care with reduced early mortality and morbidity has led to renewed interest in allogeneic transplantation in indolent lymphomas where the challenge is to select appropriate patients with high enough risk of their disease to warrant the transplant risks.

In the early 1990s the European Bone Marrow Transplant Group (EBMTG) conducted a case-controlled study in NHL matching 101 alloSCT patients with 101 autologous stem cell transplant (autoSCT) patients. Although progression-free survival was similar ( $49 \%$ alloSCT versus $46 \%$ autoSCT), there was a trend to lower relapse rate for the alloSCT patients (23\% vs 38\%). Patients with chronic GVHD had a significantly lower relapse rate than those without $(0 \%$ versus $35 \%$

Table 2 Trials employing autologous Stem cell transplant consolidation

\begin{tabular}{|c|c|c|c|c|c|}
\hline Regimen & Year & $\begin{array}{l}\text { Authorl } \\
\text { institution }\end{array}$ & $\mathbf{n}$ & PFS/EFS & Remarks \\
\hline Hyper-CVAD/MTX- & 1998 & Khouri/MD & 45 & 3 yr EFS $42 \%$ & $\mathrm{n}=25$ \\
\hline Ara-C $\rightarrow \mathrm{Cy} / \mathrm{TB}^{25}$ & & Anderson & & Median PFS 39 mos & Ist line \\
\hline \multirow[t]{2}{*}{ Various $^{26}$} & 2000 & Vose/Univ & 40 & 2 year EFS $36 \%$ & \\
\hline & & Nebraska & & & \\
\hline \multirow[t]{2}{*}{ RIT/cy/etop 27} & 2002 & Gopal/Univ & 16 & 3 year PFS $61 \%$ & All \\
\hline & & WA Seattle & & & relapsed \\
\hline \multirow[t]{2}{*}{ Various $^{23}$} & 2003 & Vandenberghe/ & 195 & 2 year PFS 55\% & \\
\hline & & EBBMT/ABMTR & & 5 year PFS 33\% & \\
\hline CHOP like induction & 2005 & Dreyling/ & 62 (ASCT) & Median PFS 39 & First line \\
\hline Dexa-BEAM $\rightarrow$ cy/TBI vs & & European $\mathrm{MCL}$ & & mos (ASCT) vs & \\
\hline $\mathrm{IFN} \alpha^{21}$ & & network & & 17 mos (IFN) & \\
\hline R-maxi-CHOP/ & 2008 & Geisler/Nordic & 160 & 6 year EFS 56\% & First line \\
\hline \multirow[t]{2}{*}{ HIDAC $\rightarrow$ BEAM $^{28}$} & & Lymphoma & & & \\
\hline & & group & & & \\
\hline R-maxi-CHOP, eto, & 2008 & Hsi/CALGB & 52 & 3 year PFS 52\%, & Stratified \\
\hline \multirow[t]{2}{*}{ MTX/HIDAC $\rightarrow$ CEP, $\mathrm{R}^{7}$} & & & & EFS $57 \%$ & by $\mathrm{Ki}-67$ \\
\hline & & & & & and PIMI \\
\hline
\end{tabular}

Abbreviations: Cy/TBI, cyclophosphamide/total body irradiation; RIT/cy/eto, radioimmunotherapy/cyclophosphamide/etoposide; HIDAC, high-dose cytarabine; BEAM, $\mathrm{BCNU} /$ etoposide/cytarabine/melphalan; $\mathrm{CHOP}$, cyclophosphamide-doxorubicin-vincristine-prednisone; MTX, methotrexate; CEP, carmustine-etoposide-cyclophosphamide; mos, months; PFS, progression free survival; EFS, event free survival. 
$P=0.02$ ) suggesting a strong graft-versus-lymphoma (GVL) effect. ${ }^{29}$ An advantage in long term survival for patients who underwent allogeneic bone manow transplant (BMT) was suggested by other nonrandomized trials. ${ }^{30,31}$ A Dutch trial involved 28 patients with recurrent or refractory low-grade NHL. The 18 patients with chemotherapy-sensitive disease underwent autoSCT and 10 patients, of whom seven were chemoresistant, underwent alloSCT. The 2 year PFS rates were $68 \%$ for alloSCT patients versus $22 \%$ for autoSCT patients $(P=0.049){ }^{31}$

Later trials concentrated on reduced intensity conditioning regimens. A fludarabine/cyclophosphamide-based regimen developed at the MD Anderson Cancer Center showed an actuarial probability for being alive and in remission at 2 years of $84 \%{ }^{32}$ An 8 year prospective study reported 47 patients treated with alloSCT using a fludarabine-cyclophosphamiderituximab (FCR) conditioning regimen. The estimated PFS rate was $83 \%$ and survival of $85 \%$ at a median follow-up time of 60 months. ${ }^{33}$ Other approaches with encouraging results include alemtuzumab-based regimens (Tables 3 and 4). ${ }^{34,35}$

\section{Allogeneic transplant in MCL}

Patients with relapsed or refractory MCL following conventional intensive chemotherapy or autoSCT have limited therapeutic options. Allogeneic transplant using myeloablative regimens was initially studied as a potentially curative approach for these patients. Because of the risks of early

Table 3 Comparison of transplant strategies in indolent NHL and $\mathrm{MCL}$

\begin{tabular}{|c|c|c|}
\hline & Allo & Auto \\
\hline Graft issues & Tumor free graft & $\begin{array}{l}\text { Potential lymphoma } \\
\text { contamination; graft } \\
\text { purging benefit not } \\
\text { yet proven }\end{array}$ \\
\hline $\begin{array}{l}\text { Mechanism } \\
\text { of effect }\end{array}$ & GVL effect & $\begin{array}{l}\text { High dose chemotherapy } \\
\text { effect }\end{array}$ \\
\hline Toxicity & $\begin{array}{l}\text { Acute and chronic } \\
\text { GVHD }\end{array}$ & $\begin{array}{l}\text { Lower acute } \\
\text { peritransplant } \\
\text { morbidity and mortality }\end{array}$ \\
\hline Efficacy & $\begin{array}{l}\text { Prolonged remission; } \\
\text { potential cure }\end{array}$ & Not generally curative \\
\hline Graft quality & Healthy donor graft & $\begin{array}{l}\text { Damage from prolonged } \\
\text { chemotherapy - risk of } \\
\text { myelodysplasia }\end{array}$ \\
\hline Recipient factors & $\begin{array}{l}\text { Limited patient population } \\
\text { (age, performance status, } \\
\text { comorbidities) }\end{array}$ & $\begin{array}{l}\text { Safer in patients who are } \\
\text { older and with } \\
\text { comorbidities }\end{array}$ \\
\hline Graft collection & Donor availability & $\begin{array}{l}\text { Stem cell collection } \\
\text { issues in heavily } \\
\text { pretreated marrows }\end{array}$ \\
\hline
\end{tabular}

Abbreviations: GVL graft versus lymphoma; GVHD, graft-versus-host disease; allo, allogeneic transplant; auto, autologous transplant. mortality and GVHD, allogeneic transplant is generally reserved for MCL patients who have relapsed after an autologous transplant and other intensive regimens. In cases of somewhat indolent progression of MCL, the less toxic RIC regimens, in which the GVL effect is thought to be the chief therapeutic effect, are attractive. However, the wide proliferative variation in MCL results in many patients whose highly proliferative disease outpaces the GVL effect following RIC regimens.

Case reports of patients with chemotherapy refractory MCL having prolonged remission after allogeneic transplant suggested a GVL effect. ${ }^{40}$ Khouri et al reported results in 16 patients bolstering the hypothesis. Of the 16 patients, 11 were previously treated; 14 were treated with myeloablative regimens - either Cy/TBI (High-dose cyclophosphamide $120 \mathrm{mg} / \mathrm{kg}$ and total body irradiation-12 Gy given in four daily fractions) or BEAM (BCNU/Etoposide/Cytarabine/ Melphalan). Overall survival and freedom from progression at 3 years was $55 \%$ and the results were even more encouraging for patients with chemotherapy sensitive disease. ${ }^{36}$ Molecular studies demonstrated that three patients with disease detectable by PCR following transplant converted to negative status several months later, suggesting a GVL effect.

Berdeja et al reported results in 35 patients with MCL and low grade lymphoma showing a 50\% event free survival at 25 months median follow-up. All grafts were from matched sibling donors and were T-cell depleted to reduce GVHD. ${ }^{37}$ This strategy had encouraging results in patients with chemotherapy-sensitive disease showing transplant related mortality (TRM) of $14 \%$ and chronic GVHD of just $6 \%$, but fared poorly in patients with resistant disease (TRM $86 \%$ and EFS of 0\%). T-cell depletion, although effective for prevention of GVHD, severely compromises the beneficial GVL effect. A promising technique under investigation to control GVH without necessarily compromising GVL involves the use of suicide gene-modified human T-lymphocytes. Herpes simplex virus-thymidylate kinase modified donor $\mathrm{T}$ cells, which play a central role in the causation of GVHD, could potentially be controlled by the addition of an antiviral drug: ganciclovir. ${ }^{41}$

The University of Nebraska reported data on outcomes in patients with chemotherapy sensitive MCL undergoing autologous $(n=80)$ versus allogeneic $(n=17)$ stem cell transplant. Five year estimated event free survival (44\% versus $39 \%$ ) and overall survival ( $49 \%$ versus $47 \%$ ) were similar in both groups. The five year relapse rate was lower at $21 \%$ in the alloSCT group, compared with $56 \%$ in the autoSCT group. This was balanced, however, by higher day 100 mortality rate in patients receiving allotransplant (19\%). These data 
Table 4 Studies of fully myeloablative regimens in mantle cell lymphoma

\begin{tabular}{|c|c|c|c|c|c|c|}
\hline Regimen & Graft source & Results & $\mathbf{n}$ & ORR & CR & Dz \\
\hline Mostly cy/TB| $\left.\right|^{36}$ & All sib donors & $3 \mathrm{yr}$ OS and & 16 & & $85.7 \%$ & II rel/ref; \\
\hline MD Anderson Cancer & & FFP $55 \%$ & & & & 5 new $D x$ \\
\hline \multicolumn{7}{|l|}{ Center } \\
\hline Mostly cy/TB| ${ }^{37}$ & All T cell depleted bone & EFS $50 \%$ at $25 \mathrm{mos}$ & 9 & & & 7 \\
\hline \multirow[t]{3}{*}{ Johns Hopkins } & marrow grafts from & median f/u; $46 \%$ & & & & chemosensitive \\
\hline & matched sib donors & TRM; Chronic & & & & \\
\hline & & GVHD 6\% & & & & \\
\hline Mostly Bu/cy ${ }^{38}$ & All matched sib donors; & Median survival & 6 & $100 \%$ & $66 \%$ & 5 relapse/ \\
\hline \multirow[t]{2}{*}{ Princess Margaret Hospital } & $5 \mathrm{BM}$ and I PBSCT & $4.3+y r s$ & & & & refractory \\
\hline & (non-myeloabl) & No TRM & & & & \\
\hline Mostly Cy/TB| ${ }^{39}$ & $88 \%$ PBSCT & 5 yr RR $21 \%$ & 17 & $65 \%$ at & $65 \%$ at & All \\
\hline \multirow[t]{2}{*}{ Univ of Nebraska } & $100 \%$ Matched sib donor & 5 yr EFS $44 \%$ & & DI00 & DI00 & chemosensitive \\
\hline & & 5 yr OS $49 \%$ & & & & \\
\hline
\end{tabular}

Abbreviations: Cy/TBI, cyclophosphamide/total body irradiation; OS, overall survival; FFP, freedom from progression; EFS, event free survival; TRM, transplant related mortality; Bu/cy, busulfan/cyclophosphamide; PBSCT, peripheral blood stem cell transplant; ORR, overall response rate; CR, complete response; Dz, disease charecteristics of patient enrolled; mos, months; GVHD, graft-versus-host disease.

emphasize the dilemma of weighing the competing risks of progressive lymphoma versus treatment-related toxicity. The high early mortality limits the possibility of including allogeneic transplant in the initial treatment regimen for patients with chemotherapy sensitive MCL (Table 5). ${ }^{39}$

Fludarabine-based RIC regimens have gained precedence over myeloablative regimens in the last decade. Sorror et al updated the Seattle experience in 2008 with 33 patients with median follow up of 63 months and an additional 20 patients with shorter follow up. All patients received a fludarabine and
$200 \mathrm{cGy}$ TBI RIC regimen. This was a heavily pretreated population in which $40 \%$ of the patients had disease progression after prior autoSCT and an additional $11 \%$ had undergone planned autoSCT before alloSCT. Five year overall and progression free survival rates were $58 \%$ and $52 \%$ respectively, and there were no major differences between the use of related and matched unrelated donors. ${ }^{46}$ At 5 years $44 \%$ were alive without GVHD, $14 \%$ with chronic GVHD requiring immunosuppression, and continued resolution of chronic GVHD was observed with time. Long term survival was achieved even in some chemotherapy-

Table 5 Results of alloSCT using reduced intensity regimens in mantle cell lymphoma

\begin{tabular}{|c|c|c|c|c|c|}
\hline Regimen & $\begin{array}{l}\text { Immuno- } \\
\text { suppression }\end{array}$ & Results & $\mathbf{N}$ & CR & Dz \\
\hline Various - mostly Flu based ${ }^{42}$ & Various & OS at I yr $38 \%$ & & & \\
\hline EBMT registry 2002 & & $\begin{array}{l}\text { PFS at I yr } 31 \% \\
\text { TRM at I yr } 46 \%\end{array}$ & 22 & & \\
\hline FCR PFA ${ }^{43}$ & Tacrolimus and & Event free survival & 18 & & 16 with \\
\hline MD Anderson Cancer Center & methotrexate & at 3 yrs $82 \%$ & 4 MUD & $94 \%$ & chemosensitive \\
\hline 2003 & & DI00 mortality 0 & I3 MRD & & $\mathrm{dz}$ \\
\hline $\mathrm{Flu} / \mathrm{mel} / \mathrm{CD} 52^{44}$ & Cyclosporine & OS at 3 yrs $60 \%$ & & & $20 \%$ NRM at \\
\hline Univ College London & $\mathrm{T}$ cell - depleting & PFS at 3 yrs $50 \%$ & 10 & & DI 00 and $3 \mathrm{yrs}$ \\
\hline 2004 & conditioning regimen & & & & \\
\hline Fludarabine and $2 \mathrm{~Gy} \mathrm{TBI^{45 }}$ & Cyclosporine/ & DFS 2 yrs $60 \%$ & 33 & & Relapsed/ \\
\hline Fred Hutchinson Cancer Center & mycophenolate & OS 2 yrs $65 \%$ & $16 \mathrm{MRD}$ & $75 \%$ & refractory \\
\hline 2004 & mofetil & NRM 2 yrs $24 \%$ & 16 MUD & & \\
\hline Fludarabine $+/-2$ Gy TBI ${ }^{46}$ & & 5 yr NRM $27 \%$ & 53 & & \\
\hline Fred Hutchinson Cancer Center & & 5 yr OS $58 \%$ & MRD 28 & & \\
\hline 2008 & & 5 yr PFS $52 \%$ & MUD 25 & & \\
\hline FCR $(86 \%)$ PFA $(14 \%)^{47}$ & Tacrolimus and & Median PFS & & & $17 \% \mathrm{rel} / \mathrm{ref}$ \\
\hline MD Anderson Cancer Center & methotrexate & $60 \mathrm{mos}$ & & & $31 \%$ CR2 \\
\hline \multirow[t]{4}{*}{2009} & & Median OS NR & 35 & & $31 \%$ CR3 \\
\hline & & $6 \mathrm{yr}$ act PFS $46 \%$ & & & \\
\hline & & 6 yr OS $53 \%$ & & & \\
\hline & & TRM at I yr $9 \%$ & & & \\
\hline
\end{tabular}

Abbreviations: FCR, fludarabine/cyclophosphamide/high-dose rituximab; PFA, cisplatin/fludarabine/cytarabine; Flu/melCD52, fludarabine, melphalan, alemtuzumab; NRM, nonrelapse mortality; MUD, matched unrelated donor; MRD, matched related donor; Dz, disease charecteristics of patients enrolled; TRM, transplant related mortality; OS, overall survival; PFS, progression free survival; CR, complete response; mos, months. 
refractory patients, but those with bulky lymphadenopathy $(\geq 5 \mathrm{~cm})$ at the time of transplant invariably did poorly.

Tam et al published updated results of a risk adapted strategy at the MD Anderson Cancer Center. Of a total of 121 patients enrolled in sequential transplant protocols over a 17 year study period, 86 underwent autoSCT. The addition of rituximab resulted in a marked PFS improvement for those getting autoSCT in CR1. There were 35 patients (median age 58 ), all with relapsed or refractory MCL, who underwent nonmyeloablative allogeneic stem cell transplant. All patients were Stage 3 or 4 and $83 \%$ had chemosensitive disease at the time of transplant ( $46 \%$ in CR). With a median follow-up of 56 months the median PFS duration was 60 months, and the median OS had not yet been reached. Major determinants of disease control were use of peripheral blood stem cells
(PBSC) versus bone marrow stem cells and achievement of $>95 \%$ donor chimerism. Among 24 patients meeting both criteria, no lymphoma relapses had occurred at a median follow-up of 60 months. ${ }^{47}$

In a retrospective study of 279 patients reported to the EBMT registry between 1998 and 2007 who had received RIC regimens in MCL, the Kaplan-Meier estimate of the PFS at 1 and 3 years was $49 \%$ and $29 \%$ respectively. The overall survival at 1 and 3 years was $60 \%$ and $43 \%$ respectively (Table 6). ${ }^{48}$

Data from the Center for International Blood and Marrow Transplant Research (CIBMTR) from 1998 to 2007 shows a steady use of related donors and increasing use of MUD donors in allogeneic transplants for MCL (written communication, January 2010). Roughly half of the 525 patients in the registry used RIC regimens for both related sibling

Table 6 Characteristics of patients with mantle cell lymphoma receiving allogeneic hematopoietic cell transplants from 1998 to 2007 and registered to the CIBMTR

\begin{tabular}{|c|c|c|c|c|}
\hline \multirow[t]{2}{*}{ Variable } & \multicolumn{2}{|c|}{ HLA-matched siblings } & \multicolumn{2}{|c|}{ Unrelated } \\
\hline & N Eval & n (\%) & N Eval & n (\%) \\
\hline Age (years) & 525 & & 203 & \\
\hline$<50$ & & $197(38)$ & & $48(24)$ \\
\hline $50-59$ & & $233(44)$ & & $92(45)$ \\
\hline $60-69$ & & $89(17)$ & & $59(29)$ \\
\hline$\geq 70$ & & $6(1)$ & & $4(2)$ \\
\hline Male & 524 & $421(80)$ & 203 & $163(80)$ \\
\hline Year of transplant & 525 & & 203 & \\
\hline 1998 & & $46(9)$ & & $2(1)$ \\
\hline 1999 & & $58(I I)$ & & $8(4)$ \\
\hline 2000 & & $65(12)$ & & $15(7)$ \\
\hline 2001 & & $65(12)$ & & $19(9)$ \\
\hline 2002 & & $43(8)$ & & $16(8)$ \\
\hline 2003 & & $63(12)$ & & $28(14)$ \\
\hline 2004 & & $45(9)$ & & $26(13)$ \\
\hline 2005 & & $63(12)$ & & $27(13)$ \\
\hline 2006 & & $45(9)$ & & $35(17)$ \\
\hline 2007 & & $32(6)$ & & $27(13)$ \\
\hline Conditioning regimen intensity & 404 & & 180 & \\
\hline Myeloablative & & $213(53)$ & & $84(47)$ \\
\hline Reduced intensity & & $191(47)$ & & $96(53)$ \\
\hline Overall survival & 525 & & 203 & \\
\hline 100-days & & $85(8 I-88)$ & & $78(72-84)$ \\
\hline I year & & $65(6 I-70)$ & & $53(46-60)$ \\
\hline 3 years & & $54(50-59)$ & & $37(30-45)$ \\
\hline Causes of death & 230 & & 121 & \\
\hline Primary disease & & $60(26)$ & & $39(32)$ \\
\hline New malignancy & & $3(1)$ & & 0 \\
\hline GvHD & & $31(13)$ & & $19(16)$ \\
\hline $\mathrm{IPn}$ & & $5(2)$ & & $5(4)$ \\
\hline Infection & & $44(19)$ & & $12(10)$ \\
\hline Organ failure & & $22(10)$ & & $21(17)$ \\
\hline Other causes & & $48(2 \mathrm{I})$ & & $20(17)$ \\
\hline Unknown & & $17(7)$ & & $5(4)$ \\
\hline
\end{tabular}

The data presented here are preliminary and were obtained from the Statistical Center of the Center for International Blood and Marrow Transplant Research. The analysis has not been reviewed or approved by the Advisory or Scientific Committee of the CIBMTR. 
and matched unrelated donors (MUD) donors and a major increase in the use of RIC regimens was seen in 2000 with roughly equal ablative and RIC regimens since that time. The median age for HLA-identical sibling donors was 53 (range 26-93) and for matched unrelated donors was 56 (range 23-72). The overall survival curves for this entire cohort are shown in Figure 1.

The CIBMTR published outcomes of stem cell transplantation subdivided by donor type and conditioning regimen as shown in Figure 2. ${ }^{49}$ Although it is difficult to make direct comparisons between the groups of patients who underwent auto versus allotransplant (selection bias - the allotransplant arm having more relapsed/refractory patients), it does give us an idea of real world outcomes. Patients who underwent autotransplant did better in the short run but seemed to have a continuing risk of relapse years post therapy. Patients undergoing allotransplant had worse survival immediately posttransplant due to short-term toxicity, but this early risk is balanced by the fact that the survival curves seem to plateau approximately 2 years later.

\section{Conclusions}

The protean nature of MCL demands individualized treatment considerations. A small subset of MCL patients can be monitored for some years without therapy. It is unclear whether indicators such as a low MIPI score or low proliferation, whether by Ki67 or gene signature, can be a guide for this most indolent population. For most patients requiring treatment the current standard, if the patient is relatively young and fit, is a dose-intense or high-dose regimen. The optimal regimen, however, is currently unknown, though most current studies include a CHOP-like regimen as well as high dose cytarabine and rituximab. With the newer intensive regimens the place of high-dose therapy with autologous stem cell support continues to be debated, though there seems to be a progression-free survival advantage in most trials. Conclusions about the place of allogeneic transplant are complicated by the paucity of data, with only a few small phase II trials directing the field. Patients whose disease progressed after autoSCT have a very poor prognosis and, if they are suitable candidates, will likely benefit from an allogeneic approach. The current data, while encouraging, are limited by small numbers of highly selected patients, and whether there will be true long-term plateau suggesting cure is unclear in the current data from the CIBMTR and others.

Though it makes intuitive sense to consider patients with high MIPI scores as candidates for allogeneic transplant upfront, especially if they are relatively young and fit and have a sibling donor, this has not been tested in comparison

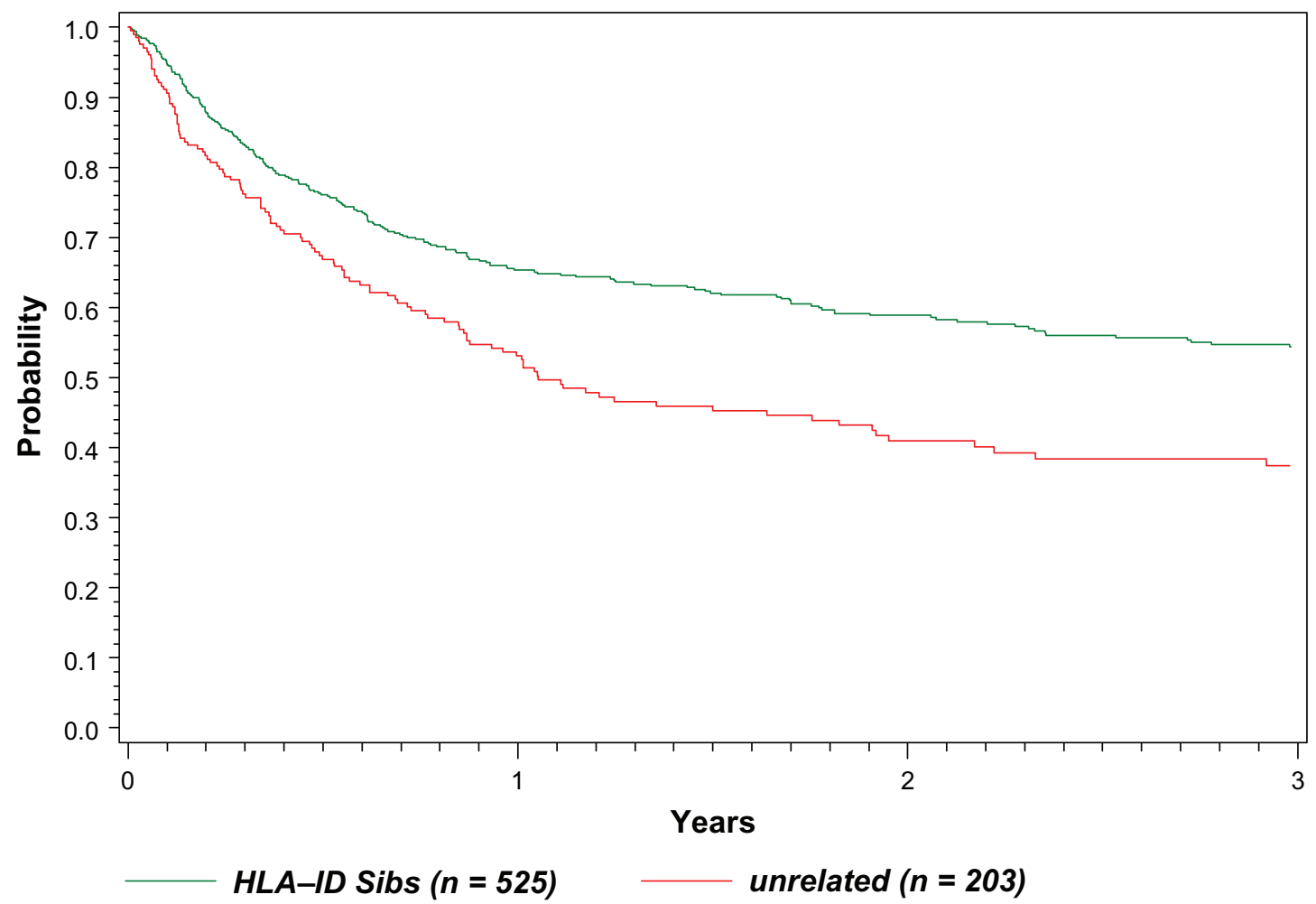

Figure I Probability of survival after transplants for Mantle Cell NHL 1998-2007. 


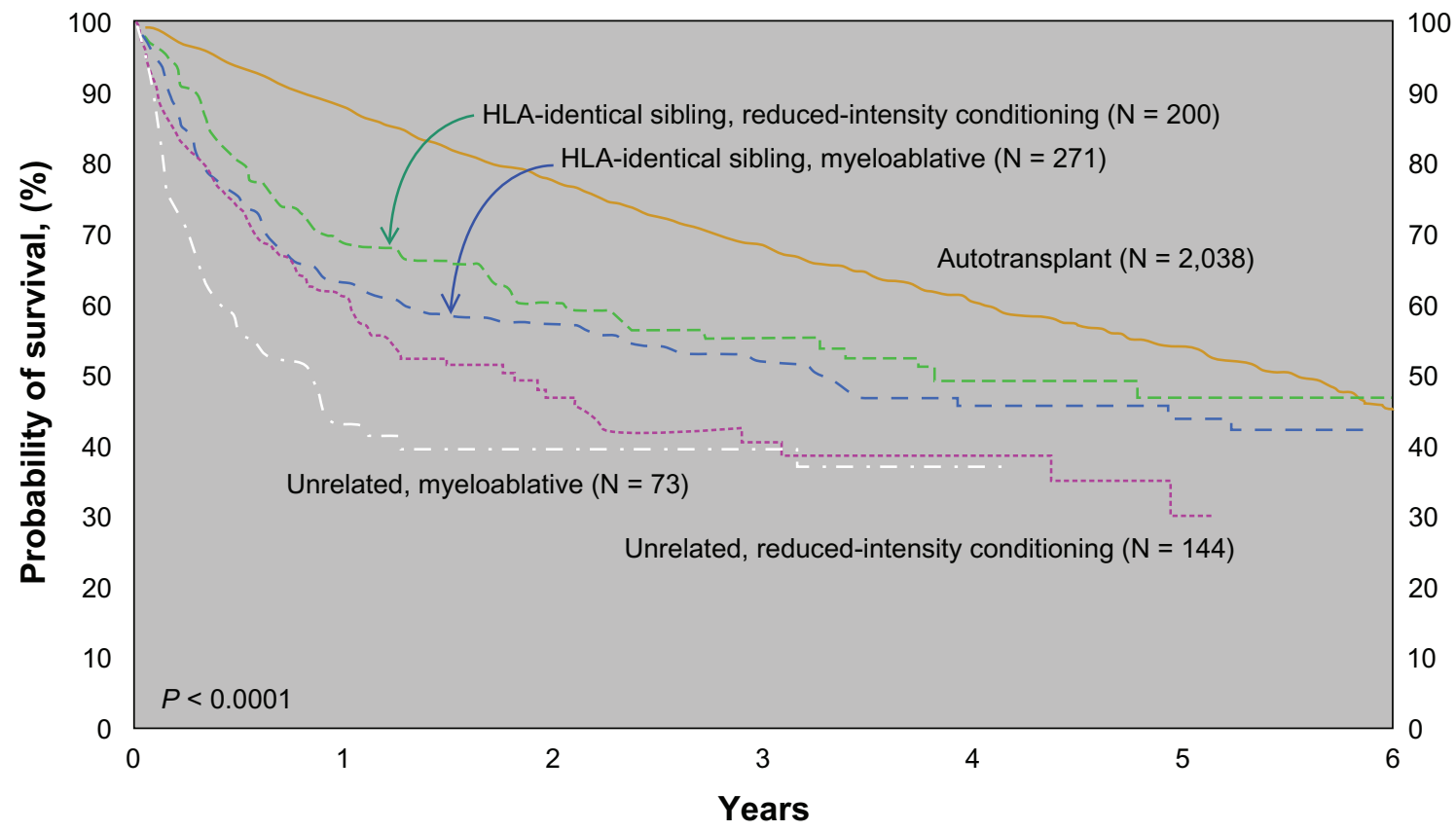

Figure 2 Probability of survival after transplants for mantle cell lymphoma, 1998-2007 by donor type and conditioning regimen. ${ }^{49}$

to autologous transplant or intensive chemotherapy (such as R-HyperCVAD) in clinical trials to date. A very high risk population in which to consider allogeneic transplant would be patients with chemoresistant disease (ideally without bulky lymphadenopathy) where autologous transplant would not likely be of benefit.

In patients with relapsed MCL with lower proliferative behavior there may be time posttransplant for the GVL effect of a RIC allogeneic transplant to develop to overcome chemoresistance. Better biologic stratification of MCL in terms of proliferative rate will be important to define this group. Certain patients, particularly those with more rapid growth and higher tumor burdens, may require more intensive conditioning regimens to optimize disease control or even a planned tandem procedure of autoSCT followed soon after with an RIC allogeneic transplant, as reported in multiple myeloma.

\section{The way forward}

Therapeutic approaches in MCL must be individualized based on both host and disease characteristics. Clear definition of the lowest risk, indolent MCL subset are needed and recommended monitoring intervals defined for this indolent group. The optimal initial therapy of MCL for those requiring treatment has not been defined in clinical trials. This is now complicated by the many new agents available for trial including bendamustine, bortezomib, lenalidomide, and radioimmunotherapy. The evolving approach is to have sepa- rate trials for older, more frail patients that incorporate novel agents. These trials will test whether these new agents can be combined with, or replace, currently used chemotherapy combinations.

For young, fit patients trials will involve dose-dense or dose-intense regimens often requiring stem cell support. Autologous SCT is currently a favored approach as consolidation of first remission or, if not utilized until that point, as part of therapy for first relapse in appropriately selected patients. Trials should be designed to optimize conditioning regimens and investigate post transplant maintenance therapy, similar to evolving trials for multiple myeloma. Radioimmunotherapy is currently being investigated as part of the conditioning regimens for both autologous and allogeneic transplantation. Furthermore, the importance of disease burden at the time of transplant should be carefully defined systematically through imaging techniques. This would allow for stratification by MIPI or other prognostic risk groups and disease burden to permit comparison of autoSCT results. The prognostic importance of achieving a minimal residual disease state in the bone marrow, assayed by flow cytometric or PCR techniques, also needs to be evaluated, perhaps serving as a surrogate marker of outcome. While it is difficult to foresee use of even RIC alloSCT as consolidation therapy of first remission MCL until toxicity and early mortality is significantly reduced, the role of alloSCT in the relapsed setting merits further exploration. Once there is a greater consensus about the optimal autoSCT regimen for MCL, a randomized 
trial comparing autologous to allogeneic transplant using a RIC regimen could be undertaken in selected patients who have relapsed after their initial therapy. Better definition of high risk features that predict poor outcome with autoSCT would be very useful. At present, allogeneic transplant trials for MCL should be restricted to appropriately selected high risk patients whose disease is relapsed/refractory post autoSCT, or demonstrates chemotherapy resistance making autoSCT a poor option.

\section{Disclosure}

The authors report no conflicts of interest in this work.

\section{References}

1. Martin P, Chadburn A, Christos P, et al. Outcome of deferred initial therapy in mantle-cell lymphoma. J Clin Oncol. 2009;27:1209-1213.

2. Hiddemann W, Longo DL, Coiffier B, et al. Lymphoma classificationthe gap between biology and clinical management is closing. Blood. 1996;88:4085-4089.

3. Tiemann M, Schrader C, Klapper W, et al. Histopathology, cell proliferation indices and clinical outcome in 304 patients with mantle cell lymphoma (MCL): a clinicopathological study from the European MCL Network. Br J Haematol. 2005;131:29-38.

4. Rosenwald A, Wright G, Wiestner A, et al. The proliferation gene expression signature is a quantitative integrator of oncogenic events that predicts survival in mantle cell lymphoma. Cancer Cell. 2003;3:185-197.

5. Rubio-Moscardo F, Climent J, Siebert R, et al. Mantle-cell lymphoma genotypes identified with $\mathrm{CGH}$ to BAC microarrays define a leukemic subgroup of disease and predict patient outcome. Blood. 2005;105:4445-4454.

6. Schaffel R, Hedvat CV, Teruya-Feldstein J, et al. Prognostic impact of proliferative index determined by quantitative image analysis and the International Prognostic Index in patients with mantle cell lymphoma. Ann Oncol. 2010;21(1):133-139.

7. Hsi ED, Jung SH, Lai R, et al. Ki67 and PIM1 expression predict outcome in mantle cell lymphoma treated with high dose therapy, stem cell transplantation and rituximab: a Cancer and Leukemia Group B 59909 correlative science study. Leuk Lymphoma. 2008;49:2081-2090.

8. Klapper W, Hoster E, Determann O, et al. Ki-67 as a prognostic marker in mantle cell lymphoma-consensus guidelines of the pathology panel of the European MCL Network. J Hematop. 2009;2:103-111

9. Hoster E, Dreyling M, Klapper W, Gisselbrecht C, et al. A new prognostic index (MIPI) for patients with advanced-stage mantle cell lymphoma. Blood. 2008;111:558-565.

10. Shah JJ, Fayad L, Romaguera J. Mantle Cell International Prognostic Index (MIPI) not prognostic after R-hyper-CVAD. Blood. 2008; 112:2583.

11. Geisler CH, Kolstad A, Laurell A, et al. The Mantle Cell Lymphoma International Prognostic Index (MIPI) is superior to the International Prognostic Index (IPI) in predicting survival following intensive firstline immunochemotherapy and autologous stem cell transplantation (ASCT). Blood. 2010;115:1530-1533.

12. Herrmann A, Hoster E, Zwingers T, et al. Improvement of overall survival in advanced stage mantle cell lymphoma. J Clin Oncol. 2009;27:511-518

13. Romaguera JE, Fayad L, Rodriguez MA, et al. High rate of durable remissions after treatment of newly diagnosed aggressive mantlecell lymphoma with rituximab plus hyper-CVAD alternating with rituximab plus high-dose methotrexate and cytarabine. J Clin Oncol. 2005;23:7013-7023.
14. Howard OM, Gribben JG, Neuberg DS, et al. Rituximab and CHOP induction therapy for newly diagnosed mantle-cell lymphoma: molecular complete responses are not predictive of progression-free survival. J Clin Oncol. 2002;20:1288-1294.

15. Lenz G, Dreyling M, Hoster E, et al. Immunochemotherapy with rituximab and cyclophosphamide, doxorubicin, vincristine, and prednisone significantly improves response and time to treatment failure, but not long-term outcome in patients with previously untreated mantle cell lymphoma: results of a prospective randomized trial of the German Low Grade Lymphoma Study Group (GLSG). J Clin Oncol. 2005;23:1984-1992.

16. Schulz H, Bohlius J, Skoetz N, et al. Chemotherapy plus Rituximab versus chemotherapy alone for B-cell non-Hodgkin's lymphoma. Cochrane Database Syst Rev. 2007;17:CD003805.

17. Schulz H, Bohlius JF, Trelle S, et al. Immunochemotherapy with rituximab and overall survival in patients with indolent or mantle cell lymphoma: a systematic review and meta-analysis. J Natl Cancer Inst. 2007;99:706-714.

18. Meusers P, Engelhard M, Bartels H, et al. Multicentre randomized therapeutic trial for advanced centrocytic lymphoma: anthracycline does not improve the prognosis. Hematol Oncol. 1989;7:365-380.

19. Nickenig C, Dreyling M, Hoster E, et al. Combined cyclophosphamide, vincristine, doxorubicin, and prednisone (CHOP) improves response rates but not survival and has lower hematologic toxicity compared with combined mitoxantrone, chlorambucil, and prednisone (MCP) in follicular and mantle cell lymphomas: results of a prospective randomized trial of the German Low-Grade Lymphoma Study Group. Cancer. 2006;107:1014-1022.

20. Smith MR, Chen H, Gordon L, et al. Phase II study of R-CHOP followed by $90 \mathrm{Y}$-ibritumomab tiuxetan in untreated mantle cell lymphoma: Eastern Cooperative Oncology Group study E1499. J Clin Oncol. 2007;24:7503.

21. Dreyling M, Lenz G, Hoster E, et al. Early consolidation by myeloablative radiochemotherapy followed by autologous stem cell transplantation in first remission significantly prolongs progressionfree survival in mantle-cell lymphoma: results of a prospective randomized trial of the European MCL Network. Blood. 2005;105: 2677-2684.

22. Pott C, Schrader C, Gesk S, et al. Quantitative assessment of molecular remission after high-dose therapy with autologous stem cell transplantation predicts long-term remission in mantle cell lymphoma. Blood. 2006;107:2271-2278.

23. Vandenberghe E, Ruiz de Elvira C, Loberiza FR, et al. Outcome of autologous transplantation for mantle cell lymphoma: a study by the European Blood and Bone Marrow Transplant and Autologous Blood and Marrow Transplant Registries. Br J Haematol. 2003;120:793-800.

24. Kolstad A, Laurell A, Andersen NS, et al. 90y-Ibritumumab Tiuxetan (Zevalin (R))-BEAM/C with Autologous Stem Cell Support as Frontline Therapy for Advanced Mantle Cell Lymphoma - Preliminary Results From the Third Nordic MCL Phase II Study (MCL3). Blood. 2009;114:932.

25. Khouri IF, Romaguera J, Kantarjian H, et al. Hyper-CVAD and highdose methotrexate/cytarabine followed by stem-cell transplantation an active regimen for aggressive mantle-cell lymphoma. J Clin Oncol. 1998;16:3803-3809.

26. Vose JM, Bierman PJ, Weisenburger DD, et al. Autologous hematopoietic stem cell transplantation for mantle cell lymphoma. Biol Blood Marrow Trans. 2000;6:640-645.

27. Gopal AK, Rajendran JG, Petersdorf SH, et al. High-dose chemoradioimmunotherapy with autologous stem cell support for relapsed mantle cell lymphoma. Blood. 2002;99:3158-3162.

28. Geisler CH, Kolstad A, Laurell A, et al. Long-term progression-free survival of mantle cell lymphoma after intensive front-line immunochemotherapy with in vivo-purged stem cell rescue: a nonrandomized phase 2 multicenter study by the Nordic Lymphoma Group. Blood. 2008;112:2687-2693. 
29. Chopra R, Goldstone AH, Pearce R, et al. Autologous versus allogeneic bone marrow transplantation for non-Hodgkin's lymphoma: a casecontrolled analysis of the European Bone Marrow Transplant Group Registry data. J Clin Oncol. 1992;10:1690-1695.

30. Ratanatharathorn V, Uberti J, Karanes C, et al. Prospective comparative trial of autologous versus allogeneic bone marrow transplantation in patients with non-Hodgkin's lymphoma. Blood. 1994;84:1050-1055.

31. Verdonck LF, Dekker AW, Lokhorst HM, Petersen EJ, Nieuwenhuis HK. Allogeneic versus autologous bone marrow transplantation for refractory and recurrent low-grade non-Hodgkin's lymphoma. Blood. 1997;90:4201-4205.

32. Khouri IF, Saliba RM, Giralt SA, et al. Nonablative allogeneic hematopoietic transplantation as adoptive immunotherapy for indolent lymphoma: low incidence of toxicity, acute graft-versus-host disease, and treatment-related mortality. Blood. 2001;98:3595-3599.

33. Khouri IF, McLaughlin P, Saliba RM, et al. Eight-year experience with allogeneic stem cell transplantation for relapsed follicular lymphoma after nonmyeloablative conditioning with fludarabine, cyclophosphamide, and rituximab. Blood. 2008;111:5530-5536.

34. Faulkner RD, Craddock C, Byrne JL, et al. BEAM-alemtuzumab reduced-intensity allogeneic stem cell transplantation for lymphoproliferative diseases: GVHD, toxicity, and survival in 65 patients. Blood. 2004;103:428-434.

35. Khouri IF, Albitar M, Saliba RM, et al. Low-dose alemtuzumab (Campath) in myeloablative allogeneic stem cell transplantation for CD52-positive malignancies: decreased incidence of acute graftversus-host-disease with unique pharmacokinetics. Bone Marrow Trans. 2004;33:833-837.

36. Khouri IF, Lee MS, Romaguera J, et al. Allogeneic hematopoietic transplantation for mantle-cell lymphoma: molecular remissions and evidence of graft-versus-malignancy. Ann Oncol. 1999;10:1293-1299.

37. Berdeja JG, Jones RJ, Zahurak ML, et al. Allogeneic bone marrow transplantation in patients with sensitive low-grade lymphoma or mantle cell lymphoma. Biol Blood Marrow Trans. 2001;7:561-567.

38. Rifkind J, Mollee P, Messner HA, Lipton JH. Allogeneic stem cell transplantation for mantle cell lymphoma - does it deserve a better look? Leuk Lymphoma. 2005;46:217-223.

39. Ganti AK, Bierman PJ, Lynch JC, Bociek RG, Vose JM, Armitage JO. Hematopoietic stem cell transplantation in mantle cell lymphoma. Ann Oncol. 2005;16:618-624.
40. Adkins D, Brown R, Goodnough LT, Khoury H, Popovic W, DiPersio J. Treatment of resistant mantle cell lymphoma with allogeneic bone marrow transplantation. Bone Marrow Trans. 1998;21:97-99.

41. Bondanza A, Valtolina V, Magnani Z, et al. Suicide gene therapy of graft-versus-host disease induced by central memory human $\mathrm{T}$ lymphocytes. Blood. 2006;107:1828-1836.

42. Robinson SP, Goldstone AH, Mackinnon S, et al. Chemoresistant or aggressive lymphoma predicts for a poor outcome following reducedintensity allogeneic progenitor cell transplantation: an analysis from the Lymphoma Working Party of the European Group for Blood and Bone Marrow Transplantation. Blood. 2002;100:4310-4316.

43. Khouri IF, Lee MS, Saliba RM, et al. Nonablative allogeneic stem-cell transplantation for advanced/recurrent mantle-cell lymphoma. J Clin Oncol. 2003;21:4407-4412.

44. Morris E, Thomson K, Craddock C, et al. Outcomes after alemtuzumab-containing reduced-intensity allogeneic transplantation regimen for relapsed and refractory non-Hodgkin lymphoma. Blood. 2004;104:3865-3871.

45. Maris MB, Sandmaier BM, Storer BE, et al. Allogeneic hematopoietic cell transplantation after fludarabine and 2 Gy total body irradiation for relapsed and refractory mantle cell lymphoma. Blood. 2004;104:3535-3542.

46. Sorror ML, Storer B, Sandmaier BM, et al. Sustained graft-versuslymphoma effect among patients (pts) with Mantle Cell Lymphoma (MCL) given nonmyeloablative allogeneic Hematopoietic Cell Transplantation (HCT). Blood. 2008;112:2147.

47. Tam CS, Bassett R, Ledesma C, et al. Mature results of the M.D. Anderson Cancer Center risk-adapted transplantation strategy in mantle cell lymphoma. Blood. 2009;113:4144-4152.

48. Robinson SP, Sureda A, Canals C Sr, et al. Identification of prognostic factors predicting the outcome of reduced intensity allogeneic stem cell transplantation in mantle cell lymphoma. An analysis from the Lymphoma Working Party of the EBMT. Blood. 2008;112:457.

49. Pasquini MC, Wang Z. Current use and outcome of hematopoietic stem cell transplantation: part II- CIBMTR summary slides. CIBMTR Newsletter. 2009;14:5-9.
Stem Cells and Cloning: Advances and Applications

\section{Publish your work in this journal}

Stem Cells and Cloning: Advances and Applications is an international, peer-reviewed, open access journal. Areas of interest in stem cell research include: Embryonic cell stems; Adult stem cells; Blastocysts; Cordblood stem cells; Stem cell transformation and culture; Therapeutic cloning; Umbilical cord blood and bone marrow cells; Laboratory,

\section{Dovepress}

animal and human therapeutic studies; Philosophical and ethical issues related to stem cell research. This journal is indexed on CAS. The manuscript management system is completely online and includes a quick and fair peer-review system. Visit http://www.dovepress.com/ testimonials.php to read real quotes from published authors. 